\title{
Further Development and Flight Test of an Autonomous Precision Landing System Using a Parafoil
}

James E. Murray, Alex G. Sim, David C. Neufeld, Patrick K. Rennich, Stephen R. Norris, and Wesley S. Hughes

July 1994

(NASA-TM-4599) FURTHER DEVELOPMENT

AND FLIGHT TEST OF AN AUTONOMOUS PRECISION LANDING SYSTEM USING A PARAFOIL (NASA. Dryden Flight Unclas Research Facility) $12 \mathrm{p}$

$H 1 / 02 \quad 0013485$

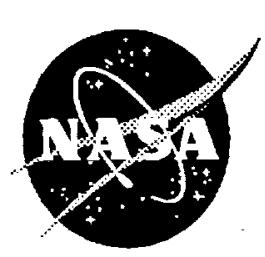


c. .

$=$ 
NASA Technical Memorandum 4599

\section{Further Development and Flight Test of an Autonomous Precision Landing System Using a Parafoil}

James E. Murray, Alex G. Sim, David C. Neufeld, Patrick K. Rennich, Stephen R. Norris, and Wesley S. Hughes

Dryden Flight Research Center

Edwards, California

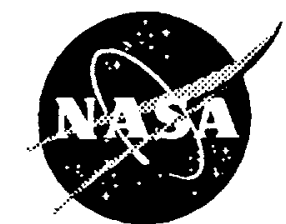

National Aeronautics and Space Administration

Office of Management

Scientific and Technical Information Program 


\title{
FURTHER DEVELOPMENT AND FLIGHT TEST OF AN AUTONOMOUS PRECISION LANDING SYSTEM USING A PARAFOIL
}

\author{
James E. Murray,"Alex G. Sim,"David C. Neufeld, \\ Patrick K. Rennich, ${ }^{c}$ Stephen R. Norris, and Wesley S. Hughes ${ }^{b}$ \\ NASA Dryden Flight Research Center \\ P.O. Box 273 \\ Edwards, California 93523-0273
}

\begin{abstract}
NASA Dryden Flight Research Center and NASA Johnson Space Center are jointly conducting a phased program to determine the feasibility of the autonomous recovery of a spacecraft using a ram-air parafoil system for the final stages of entry from space to a precision landing. The feasibility is being studied using a flight model of a spacecraft in the generic shape of a flattened biconic that weighs approximately $120 \mathrm{lb}$ and is flown under a commercially available ram-air parafoil. Key components of the vehicle include the Global Positioning System (GPS) guidance for navigation, a flight control computer, an electronic compass, a yaw rate gyro, and an onboard data recorder. A flight test program is being used to develop and refine the vehicle. The primary flight goal is to demonstrate autonomous flight from an altitude of $3,000 \mathrm{~m}(10,000 \mathrm{ft})$ with a lateral offset of $1.6 \mathrm{~km}(1.0 \mathrm{mi})$ to a precision soft landing. This paper summarizes the progress to date. Much of the navigation system has been tested, including a heading tracker that was developed using parameter estimation techniques and a complementary filter. The autoland portion of the autopilot is still in development. The feasibility of conducting the flare maneuver without servoactuators was investigated as a means of significantly reducing the servoactuator rate and load requirements.
\end{abstract}

\footnotetext{
"Aerospace Engineer.

BAerospace Technician.

'Electronic Engineering Student.

dAerospace Engineering Student.

Copyright $\odot 1994$ by the American Institute of Aeronautics and Astronautics, Inc. No copyright is asserted in the United States under Title 17, U.S. Code. The U.S. Government has a royalty-free license to exercise all rights under the copyright claimed herein for Govemmental purposes. All other rights are reserved by the copyright owner.
}

\section{Nomenclature}

$\begin{array}{ll}\text { Acronyms } & \\ \text { CPT } & \text { control position transducer } \\ \text { CPU } & \text { central processing unit } \\ \text { GPS } & \text { Global Positioning System } \\ \text { PID } & \text { proportional integral derivative } \\ \text { Symbols } & \\ K & \text { gain factor } \\ k & \text { discrete time index } \\ r & \text { yaw rate, rad/sec } \\ t & \text { time, sec } \\ \delta_{a} & \text { aileron, centimeters of differential control line } \\ \zeta & \text { damping ratio } \\ \tau & \text { filter time constant, sec } \\ \Psi & \text { heading angle, rad } \\ \omega_{n} & \text { natural frequency, rad/sec }\end{array}$

\section{Subscripts}

$\begin{array}{ll}\text { comp } & \text { compass measurement } \\ \text { filt } & \text { filter } \\ \text { gyro } & \text { rate gyro measurement } \\ \text { lim } & \text { limit }\end{array}$

\section{Introduction}

NASA is studying a variety of vehicle concepts for returning humans and cargo from space. One option is a deployable parafoil used as a landing system during the final stages of entry. To demonstrate this option, NASA Dryden Flight Research Center, Edwards, California, and NASA Johnson Space Center, Houston, Texas, are conducting the Spacecraft Autoland Project. This project 
uses a subscale generic spacecraft shape (spacewedge) that is flown under a ram-air parachute. The spacewedge contains a flight control computer, actuators, and sensors that include a Global Positioning System (GPS) receiver for navigation. For this study, the feasibility demonstration would consist of autonomous navigation and soft landing at a selected landing site after deploying the vehicle at 3,000-m (10,000-ft) altitude with a lateral offset of at least $1.6 \mathrm{~km}(1 \mathrm{mi})$. The required precision is to land within $0.4 \mathrm{~km}(0.25 \mathrm{mi})$ of the target landing coordinates. Other potential uses for this technology include offset cargo delivery from aircraft and recovery of high-altitude balloon payloads.

Limited resources strongly influenced the project's scope and design philosophy. A personnel-sized test article was needed to remain within the project's scope. The vehicle simplified flight operations because it was small enough for two to three people to handle. The size and weight of the batteries, instrumentation, and other systems were not an issue because of the vehicle's adequate dimensions. A parafoil was chosen from a large selection of commercially available ram-air parachutes. Flight operations were conducted at a nearby sport skydive facility using proven deployment techniques and eliminating the need to use a military drop zone.

\section{Phase 1}

The first phase, conducted from October 1991 to March 1993, provided confidence in applying a navigation system to a vehicle flown under a ram-air parachute. ${ }^{1}$ The flight vehicle, which was about $1.2 \mathrm{~m}$ (4 ft) long and weighed $68 \mathrm{~kg}(150 \mathrm{lb})$, was flown under a $26.8-\mathrm{m}^{2}$ $\left(288-\mathrm{ft}^{2}\right)$ ram-air parachute to yield a wing loading near $2.4 \mathrm{~kg} / \mathrm{m}^{2}\left(0.5 \mathrm{lb} / \mathrm{ft}^{2}\right)$. This wing loading is similar to that used by a student parachutist but lower than would be used for actual spacecraft recovery. The low wing loading provided an extra measure of safety for the phase-1 flights. As a cost-saving measure, commercially available hardware (i.e., the flight actuators and sensors) was used where available. The flight control computer and its related software were contracted out.

A flight test program was used to develop and refine the phase-1 vehicle. The development included several ground tests and manual flight using a radio uplink. The last 4 flights of a total of 36 were used to demonstrate the autonomous system. One flight was conducted in flight conditions with winds that were, at times, equal to the vehicle airspeed. This particular flight was launched from an altitude of $3,000 \mathrm{~m}(10,000 \mathrm{ft})$ with a lateral offset of $2.7 \mathrm{~km}(1.7 \mathrm{mi})$.

\section{Phase 2}

The second phase, which began in March 1993 and is still in progress (March 1994), has similar demonstration objectives. The primary objective is to accomplish a flight demonstration similar with that flown in the first phase but with a wing loading representative of a full-scale spacecraft. An $8.2-\mathrm{m}^{2}\left(88-\mathrm{ft}^{2}\right)$ personnel-sized parachute is being used with a similar $54-\mathrm{kg}$ (120-lb) personnel-sized flight vehicle to attain a wing loading of $6.8 \mathrm{~kg} / \mathrm{m}^{2}(1.4 \mathrm{lb} /$ $\left.\mathrm{ft}^{2}\right)$. The vehicle will be ballasted to $79 \mathrm{~kg}(175 \mathrm{lb})$ to achieve the desired wing loading of $9.8 \mathrm{~kg} / \mathrm{m}^{2}\left(2 \mathrm{lb} / \mathrm{ft}^{2}\right)$. Phase 2 also includes upgraded control algorithms and an upgraded flight control computer.

The small, personnel-sized parafoil limits the applicability of the research findings. Some of the critical issues of large-scale parafoil systems (such as weak directional control authority) are not being addressed in this project. Two critical issues for the phase- 2 system that are unrelated to full-scale parafoils are sensitivity to directional control (characteristic of smaller highly-loaded parafoils ${ }^{2}$ ) and a directional trim that changes from flight to flight. These have caused the project significant development problems even though they are mostly nonissues on the large-scale systems. For example, the phase-1 vehicle, with its larger parafoil, used an open-loop controller to steer the vehicle. The phase-2 vehicle cannot use that approach because of the changing directional trim. Some critical issues (such as the selection of a navigation technique) and the design process for the phase- 2 system are independent of scale.

The design process revolved around treating the test article as a research aircraft. To understand vehicle dynamics, instrumentation (in addition to that needed for autonomous flight) was added to collect dynamic data for postflight analysis. Parameter estimation techniques ${ }^{3}$ were used to obtain a dynamic model of the combination parafoil and spacewedge vehicle for control system design and analysis. Compared with NASA Dryden's piloted research aircraft projects, some instrumentation sensors on the autonomous system were of relatively low cost and quality. Postflight data analysis and reconstruction techniques were used to develop real-time algorithms for sensor data-quality enhancements.

A separate, phase- 2 objective is to investigate landing flare techniques that do not rely on the primary servoactuators (servos). Actuator rate and power requirements for navigation are relatively modest and allow for the use of small actuators. The rate and power requirements to actuate the flare are much greater. If actuators are sized for the flare task, then they are grossly oversized for the 
navigation task. Real weight and power benefits can be derived from eliminating the use of actuators to flare the vehicle, particularly for large-scale systems.

This paper documents the phase- 2 development and flight test of an autonomous precision landing system using a parafoil. Although the autonomous flight demonstration all the way to touchdown has not yet been accomplished, several key tasks have been completed and are reported in this paper. These include much of the development and flight validation of the autonomous navigation system and the development of the alternative flare system. The autonomous flare and landing system is still being developed.

\section{Vehicle Description}

The spacewedge vehicle, shown in figure 1, comprises a flattened biconic airframe that was joined to a ram-air parafoil with a custom harness. In the manual control mode, the vehicle was flown using a radio uplink. In the autonomous mode, the vehicle was controlled by a small onboard computer that received inputs from flight sensors. Selected data also were recorded by the onboard flight control computer.

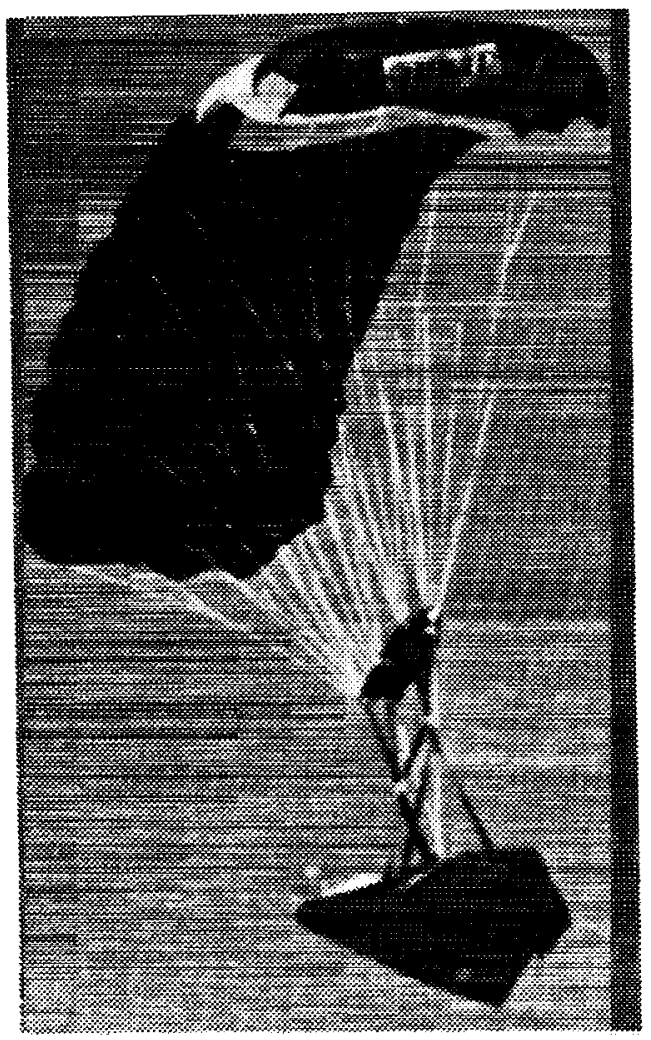

EC 93 41085-7

Figure 1. Spacewedge vehicle in flight.

\begin{tabular}{ll}
\hline \hline \multicolumn{2}{c}{ Physical characteristics. } \\
\hline Vehicle & $1.15 \mathrm{~m}(4 \mathrm{ft})$ \\
Length, vehicle only & $1.27 \mathrm{~m}$ \\
Length, with packed parachute & $0.55 \mathrm{~m}$ \\
Height & $0.80 \mathrm{~m}$ \\
Span & $0.046 \mathrm{~m}$ \\
Nose radius & $36^{\circ}$ \\
Total cone angle, forebody & $33^{\circ}$ \\
Total cone angle, aft body & $0.33 \mathrm{~m}^{2}$ \\
Base area & $54 \mathrm{~kg}(120 \mathrm{lb})$ \\
Weight & \\
Parachute & $4.5 \mathrm{~m}$ \\
Span & $1.6 \mathrm{~m}$ \\
Chord, actual & $7.2 \mathrm{~m}^{2}\left(77 \mathrm{ft}^{2}\right)$ \\
Area, actual & $8.2 \mathrm{~m}^{2}\left(88 \mathrm{ft}^{2}\right)$ \\
Area, reference & 9 \\
Cells & $0.0045 \mathrm{~m}^{3}$ \\
Pack volume & $2.3 \mathrm{~kg}^{\text {Weight }}$ \\
\hline \hline
\end{tabular}

The spacewedge is roughly $1.2 \mathrm{~m}(4 \mathrm{ft})$ long and weighs $54 \mathrm{~kg}(120 \mathrm{lb})$. The table shown provides a detailed list of the physical characteristics. A flattened biconic was chosen as a representative hypersonic shape for the vehicle although the aerodynamics of any hypersonic shape will have only minor effects on the flying qualities while under a parafoil. The primary structure was plywood with fiberglass reinforcing because it had to withstand hard landings. Where possible, vehicle costs, cosmetics, and complexitics were limited. In addition, the project benefited from keeping the value of the vehicle low because the need for system redundancy was diminished.

Alternative flare hardware (fig. 2) was added to the phase-1 vehicle airframe for the phase- 2 tests. The system used the vehicle's weight to actuate two control levers that were attached to the front hamess lines. The levers were attached to an overcenter pivot and pulled down the two control lines with the release of a securing pin. The levers were fixed for most of the flight and released at approximately $10 \mathrm{ft}$ of altitude. With the release of the pin, both control lines were pulled to the full brake position and the vehicle flared. Flight testing was accomplished in the manual mode.

The parafoil chosen for the phase- 2 tasks is a ram-air parachute with a reference area of $8.2 \mathrm{~m}^{2}\left(88 \mathrm{ft}^{2}\right)$. The reference area includes the cutaway leading edge leaving an actual area of roughly $7.2 \mathrm{~m}^{2}\left(77 \mathrm{ft}^{2}\right)$. Similar parachutes are used for advanced sport skydiving. The flare maneuver requires control line pull of $38 \mathrm{~cm}$ (15 in.) with a peak 


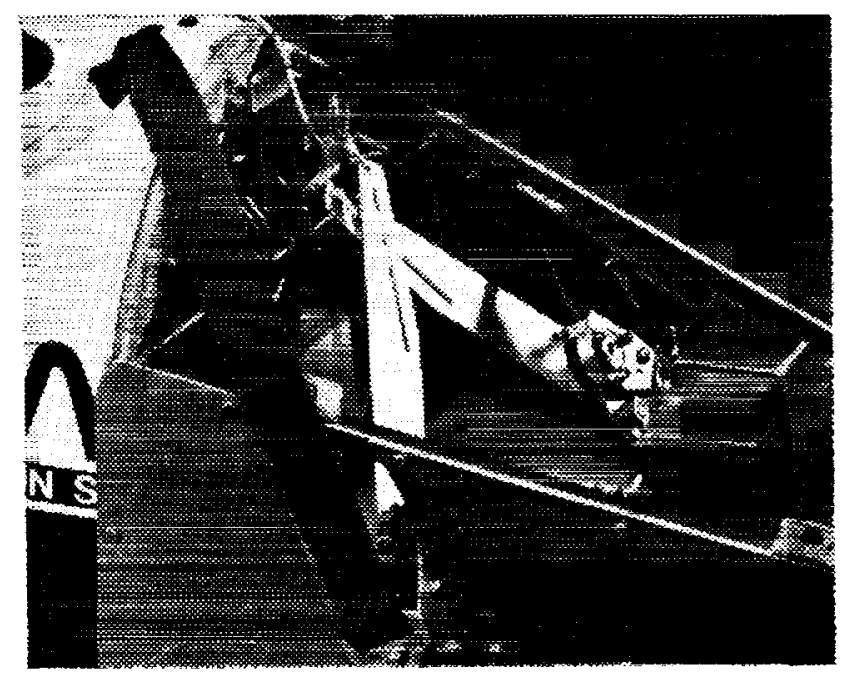

EC 94 42443-4

Figure 2. Alternative flare mechanism.

of approximately $4.5 \mathrm{~kg}(10 \mathrm{lb})$ of force. In parafoil terminology, "full brake" refers to the condition of fully retracted (pulled) control lines and results in vehicle flare, while "full flight" refers to fully extended control lines and results in high-speed flight. With the exception of lengthened control lines, the parachute rigging has not been modified. Lengthened control lines have been attached to servo arms. A fabric-sliding device called a "square slider," which is traditionally used to soften the opening loads of ram-air parachutes, has been retained.

\section{Instrumentation and Control System}

The instrumentation and control system are integrated into one processor. Figures 3 and 4 show a conceptual block diagram and photo of the system. The main central processing unit is a commercial single-board computer using a MC 68332 microcontroller. This board is supplemented with several NASA Dryden-designed and manufactured interface boards for providing power, processing analog and digital sensor data, and controlling actuators.

Several commercial sensors are used including the GPS receiver, rate gyros, electronic compass, and absolute pressure transducer. The GPS receiver is a primary sensor, providing time, position, and velocity information ${ }^{4}$ to the computer. The GPS hardware is a commercially available, 5-channel, coarse acquisition code receiver. NASA Dryden-developed sensors include the control position transducers (CPTs) and a true airspeed system consisting of an optical counter to measure the revolutions of a small impeller. The true airspeed sensor has been added for system development only.

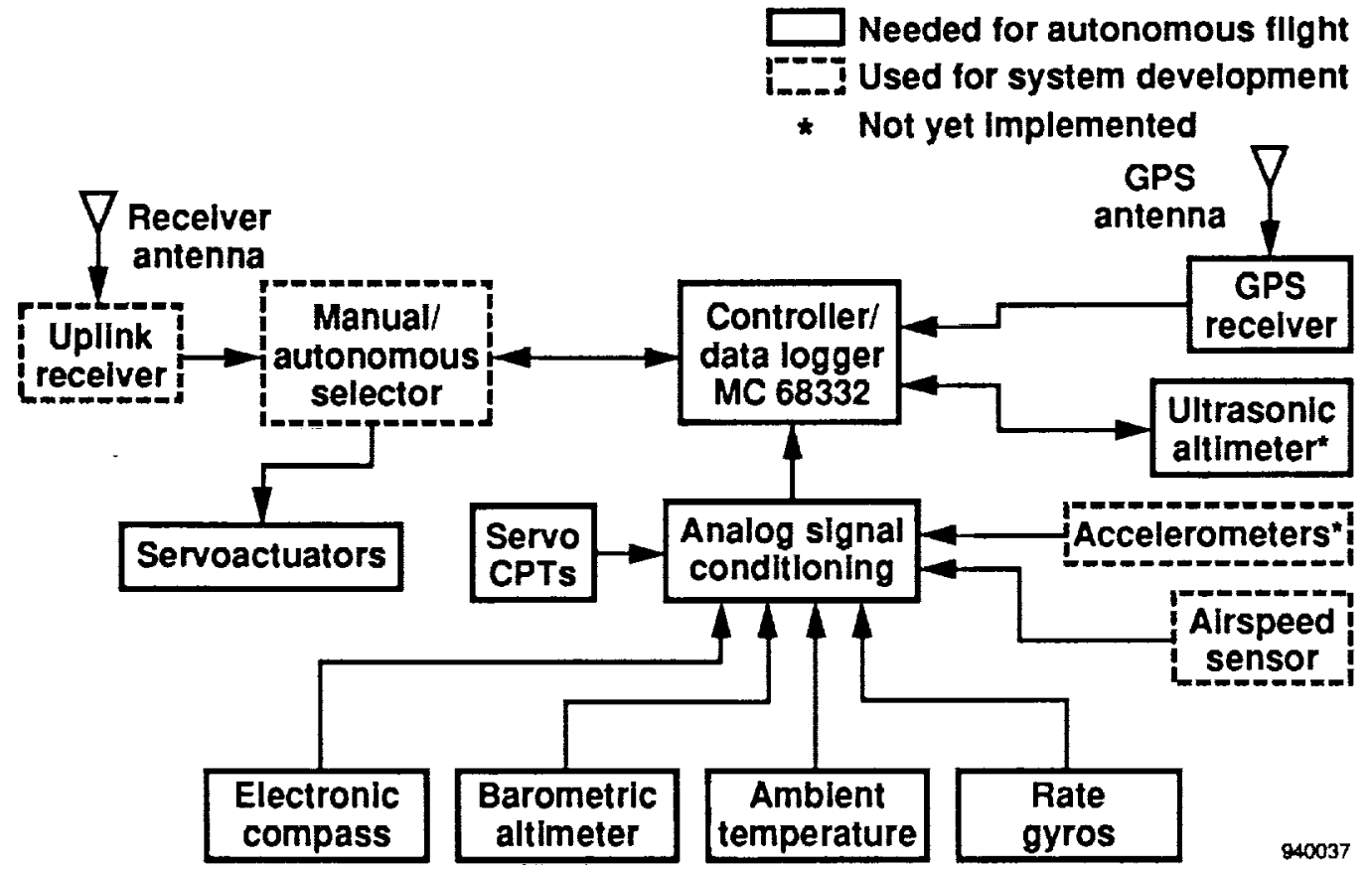

Figure 3. Spacewedge instrumentation and flight control system. 


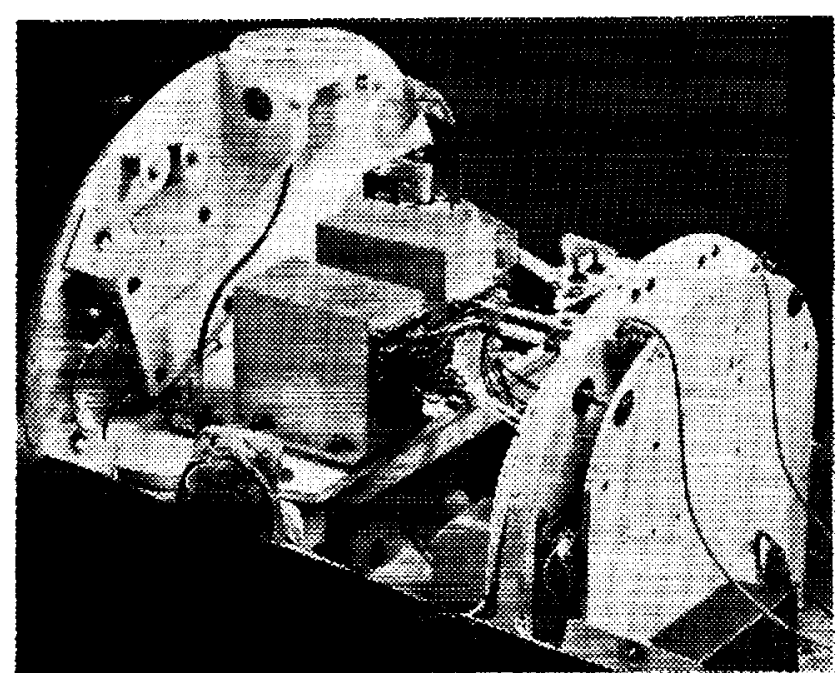

EC 94 42443-5

Figure 4. Spacewedge hardware systems.

Two large commercial servos are used to control the vehicle. Each servo has $3.8 \mathrm{~m}-\mathrm{kg}(27.5 \mathrm{ft} \cdot \mathrm{lb})$ of torque and is controlled using a pulse-width-modulation signal compatible with the uplink receiver used for manual-mode flying. Mechanizing one servo for each control line has the advantage of electronically controlling both symmetric and differential deflection of the control lines. Thus, it is easy to change control authority and trim settings through software. Two servos also provide for redundancy so that nonprecision control may be maintained even with the failure of one servo. With the small, phase-2 parachute, lever arms have been attached to the servos and further simplify the system.

The control system has a selectable manual or autonomous flight mode via a hardware switch controlled by the uplink system. With this hardware switch, manual control is maintained in the event of a flight control computer failure. The hardware switch was developed at NASA Dryden and is considered a safety feature for the development flights. The manual mode uses a radio-controlled model receiver and uplink transmitter. The uplink signal is boosted to $15 \mathrm{~W}$, and a govemment-authorized frequency is used.

A ground-based laptop computer initializes and configures the flight control computer. Initialization includes the target landing coordinates. After each flight, the laptop is used to download the onboard recorded flight data for further analysis.

Figure 5 shows the conceptual software flow diagram for the flight control computer. The integration of the instrumentation and control tasks into one processor divides the needed software into two tasks: logging flight data and running the autopilot control laws. All of this software has been developed at NASA Dryden and programmed in the $C$ language. Most flight data are logged at

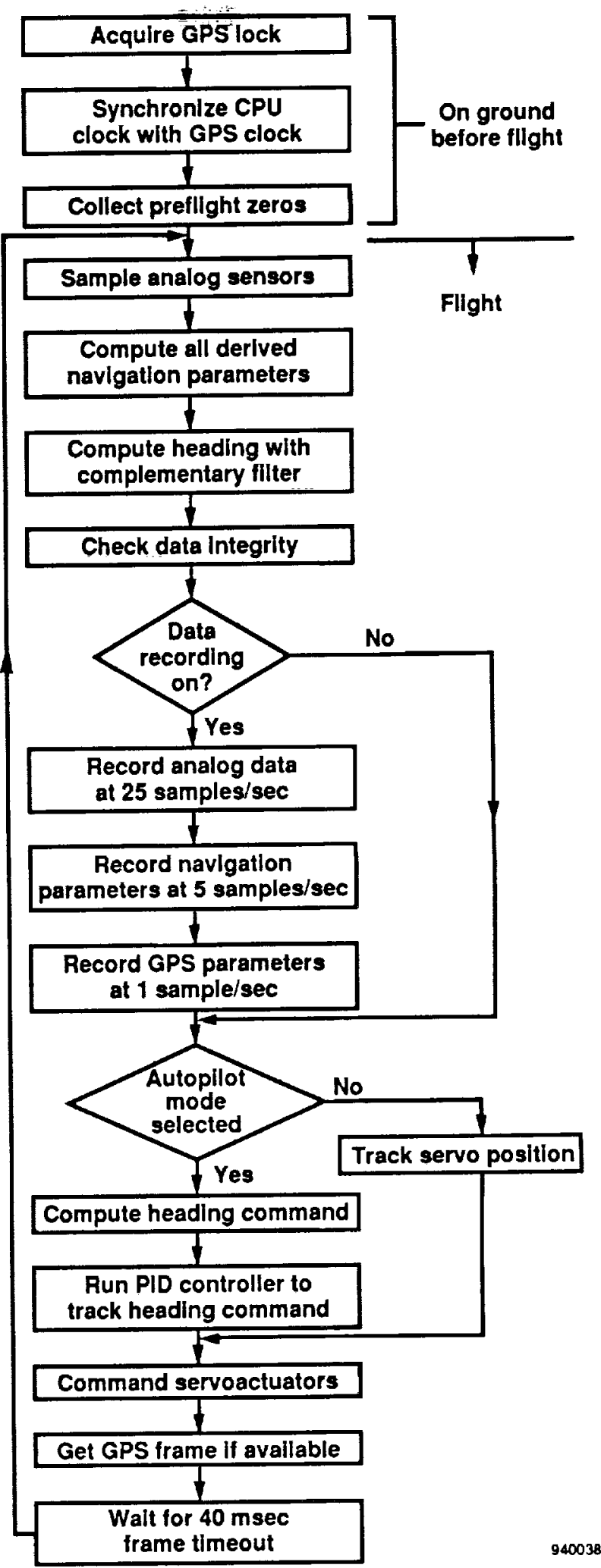

Figure 5. Spacewedge software flow diagram.

25 samples/sec; the GPS data are logged at 1 sample/sec. The critical internal control system variables used to determine control system performance are logged at 5 samples/sec. All logged data are time tagged using the GPS time code. The inner control loop is performed at 25 frames/sec. 


\section{Ground Tests}

Ground tests have been conducted with the spacewedge mounted on a rack on top of a van (fig. 6). The test objectives were to calibrate the true airspeed sensor and to validate the system hardware and software in a simulated flight environment. Most of these tests have been conducted while driving the van on the dry lakebed of Rogers Lake.

During the development part of the flight program an impeller (fig. 7) has been used as a true airspeed sensor: it is deployed (rotated up into the airstream) after the parachute has fully opened and is retracted before landing. The impeller will be removed for the final demonstration flights. An on-the-ground calibration of the sensor was necessary to account for the local flow effects around the spacewedge. Prior flow studies ${ }^{5}$ with the van have shown the upwash angle at the spacewedge's mounting position to be $7^{\circ}$. To simulate the spacewedge's nominal flight angle of attack of $17^{\circ}$, the vehicle is mounted on the van's rack at a $10^{\circ}$ angle. The calibration is assumed to be valid only for small angles of sideslip.

In relatively calm wind conditions, the van performed acceleration-deceleration test runs upwind and downwind on the lakebed to calibrate the airspeed. The time-synchronized, air-relative velocity from the impeller probe and the ground-relative velocity from the GPS receiver were recorded on board the flight control computer. A collective analysis of a pair of accelerationdeceleration runs in the upwind and downwind directions allowed separate identification of impeller offset, scale factor, GPS time lag, and windspeed in the calibration process. An analysis of time history data showed significant time lag in the GPS-derived velocity (fig. 8). From these runs, a lag loop is shown in the crossplot of the GPS velocity and impeller airspeed (fig. 9). Next, cross-correlation techniques were used to identify the time lag in the GPS velocities: estimates ranged from 2.0 to 2.3 sec. The data were then resynchronized to account for the lag, and a linear curve fit was applied to complete the calibration (fig. 10). The root-mean-square error in the calibration is about $0.6 \mathrm{~m} / \mathrm{sec}$.

The vehicle's hardware and software were partially tested before flight by performing a flight simulation with the spacewedge mounted on top of the van rack. In this position, both the GPS and electronic compass had an unobstructed view of the sky. Left and right steering lines (attached to the spacewedge's control lines) were suspended in front of a driver who, while driving at a nominal velocity, steered according to the control line positions. A van passenger watched for obstacles on the lakebed. A "back-seat pilot" in the van used a radio control transmitter to select the manual and autonomous modes of the autopilot. When the spacewedge's autopilot could steer

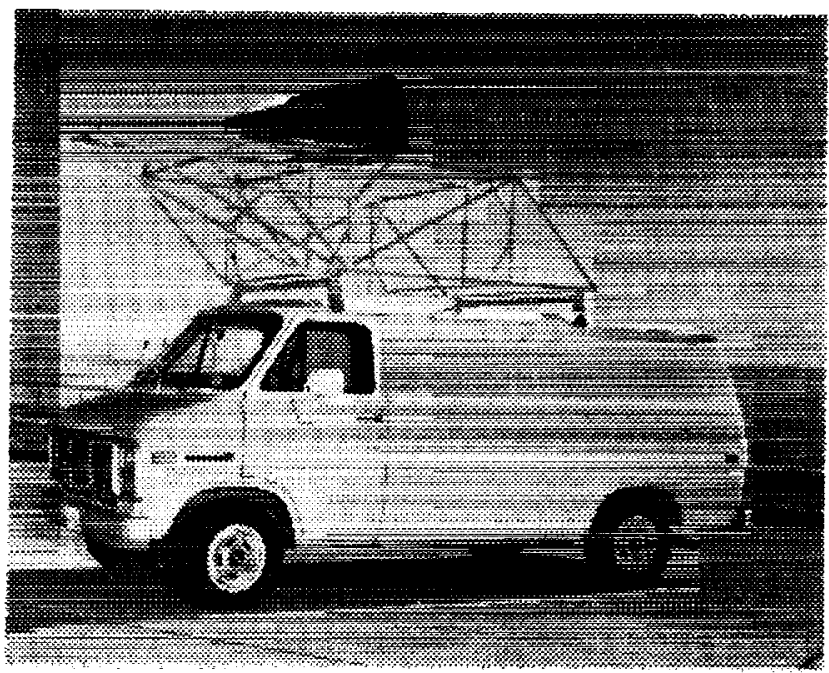

EC 94 42443-1

Figure 6. Ground test van with rack and spacewedge.

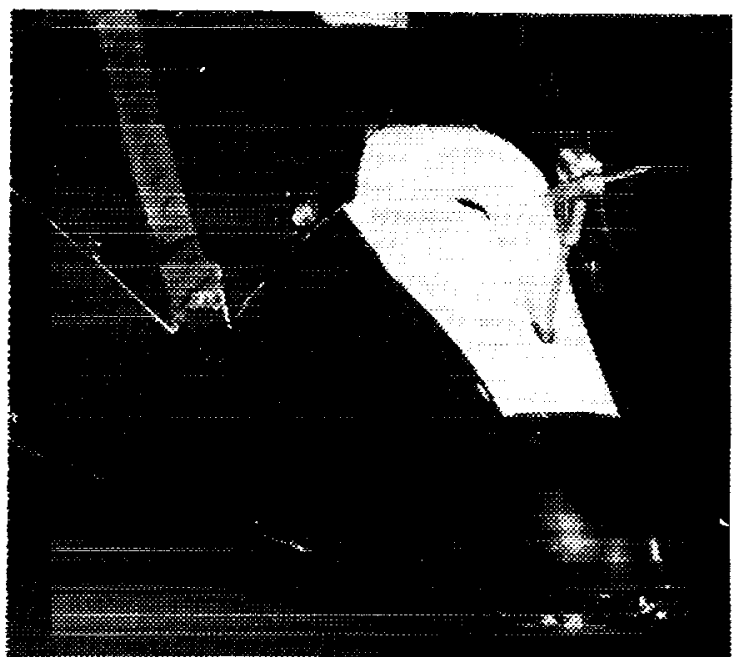

EC 94 42443-3

Figure 7. True airspeed impeller.

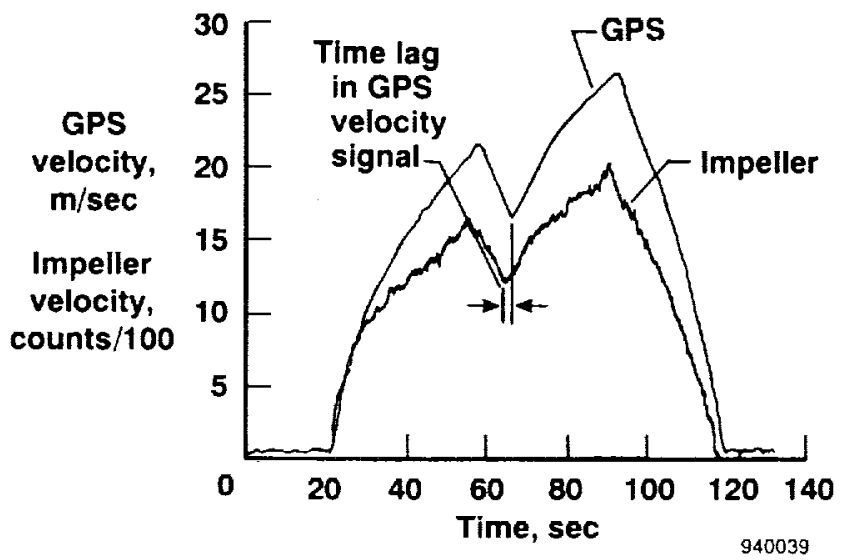

Figure 8. Ground-relative velocity from the GPS sensor and uncalibrated velocity from the impeller. 


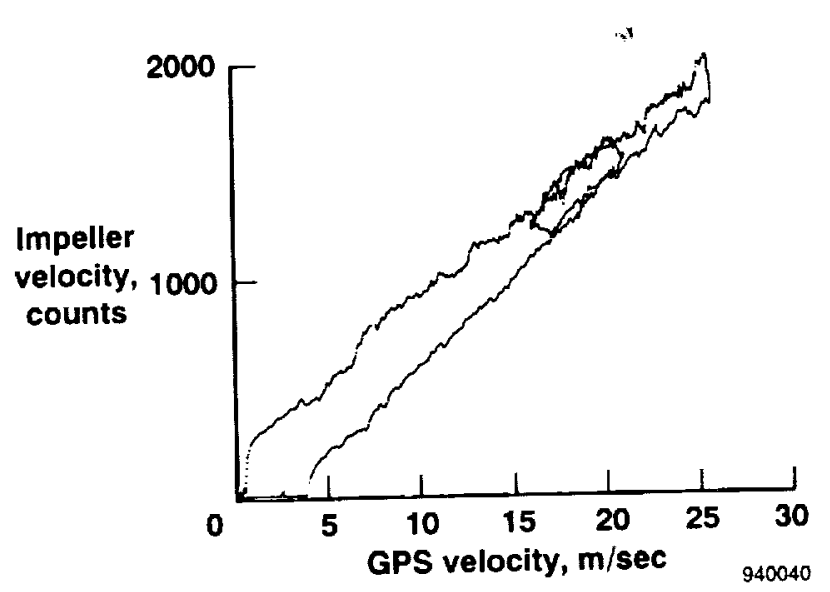

Figure 9. Crossplot of GPS velocity and uncalibrated velocity from airspeed impeller showing relative time lag.

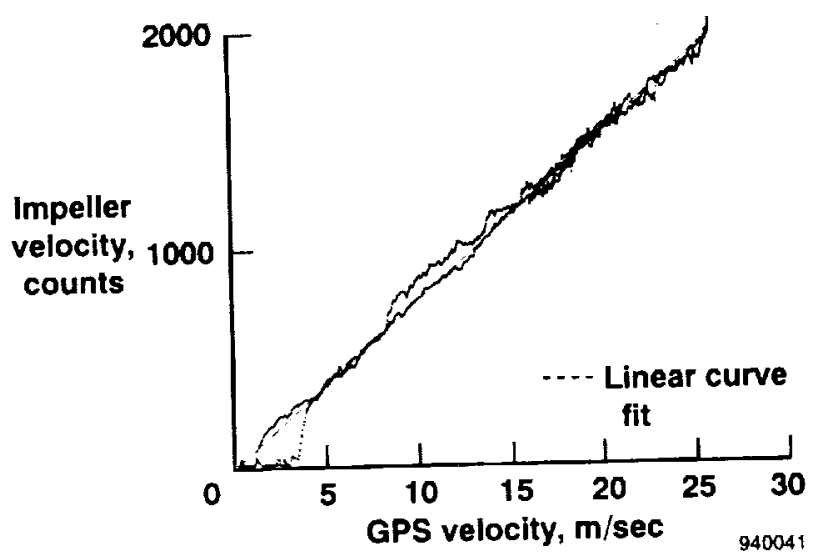

Figure 10. Crossplot of GPS velocity (corrected for time lag), uncalibrated velocity from airspeed impeller, and linear calibration curve fit.

the van to a preselected target on the lakebed, the ground test was considered successful. Although this is a relatively efficient way to validate much of the hardware and software, it does not substitute for flight tests. In flight, the effects of winds, trim offsets, and sensor degradation during maneuvering can be significant.

\section{Flight Test Techniques}

Several flight test operations were conducted to develop and refine the control system. Before each flight, control software (including target landing coordinates) was uploaded from the laptop computer to the flight control computer. Once useful GPS reception (lock) was obtained, preflight tare values (zeros) were taken for altitude, ambient temperature, and yaw rate. The spacewedge was then loaded into the launch airplane. Because maintaining good reception was impossible inside the launch vehicle, GPS lock would be lost for as long as 15 min during the climbout of the launch vehicle. The lock would typically not be reacquired until approximately $40 \mathrm{sec}$ after launch. It was normal to wait at least $1 \mathrm{~min}$ after launch either to start collecting data or to enter the autonomous control mode. If GPS lock was not acquired when the autopilot mode was engaged, the vehicle would enter a circling pattern. Other operational procedures such as deploying the parachute and clearing the control lines remained unchanged from the phase-1 demonstration.'

The development flights were launched from $1800 \mathrm{~m}$ $(6000 \mathrm{ft})$ above the ground with an offset from the landing site that varied between 0.8 and $1.6 \mathrm{~km}(0.5$ and $1 \mathrm{mi})$. Total flight time was about $6 \mathrm{~min}$. Data maneuvers or autopilot evaluation started after the first minute and lasted for the next 2 to $3 \mathrm{~min}$. The remaining flight time was used to safely return the vehicle to the landing site.

Manual flying was used for all the development flights. Onboard systems were added incrementally and validated independently in a flight environment. For the first two flights, only the uplink receiver and servos were installed. The flight control computer was added starting with the third flight, but it was only used as a datalogger for the sensors that were on board. By flight 10, the GPS system was added; the yaw rate gyro and airspeed sensor were added at flight 16. Besides system checkout, many data maneuvers were performed during the development flights. Several flight test maneuvers were performed on flights 17 through 19 to identify the vehicle's directional dynamics. These maneuvers comprised differential control line inputs of steps and pulses of various amplitude and duration.

\section{Flight Test Results}

Limited flight testing of the autonomous mode has been accomplished. A flight-to-target control mode has been demonstrated. Winds have been computed on board and logged into the data system, but not yet actually used by the autopilot.

Key to the navigation tasks in the autonomous control mode is the capability to track heading. Changes in heading are effected by differential control of the parafoil's trailing edges and is referred to here as an aileron input. The design of a heading tracker requires a model of the directional dynamics of the spacewedge and parafoil system. Rather than work from first principles to derive a full multiple-degree-of-freedom model of the dynamics of the two-body system, the project used flight data to identify the simplest model that would capture those dynamic elements essential to designing a heading tracker.

\section{Dynamic Modeling}

Parameter estimation techniques ${ }^{3}$ were used postflight to analyze the recorded data from several directional step and pulse maneuvers. A second-order model 
with aileron as input and yaw rate as output yielded estimates of control gain, system natural frequency, and damping. Figures 11(a) and (b) compare the measured and estimated (modeled) yaw rate response with the aileron input for two maneuvers. Note that the second-order model tracks the primary characteristics of the measured response resulting from the aileron input while successfully ignoring the turbulence-driven response at about $16 \mathrm{sec}$ in figure 11(b). The results of many maneuvers were averaged to yield a transfer function estimate (shown below) that was used in the control law design.

$$
\frac{r(s)}{\delta_{a}(s)}=\frac{K_{\delta_{a}}}{s^{2}+2 \zeta \omega_{n} s+\omega_{n}^{2}}
$$

where $K_{\delta_{a}}=0.6, \omega_{n}=2.5$, and $\zeta=0.3$.
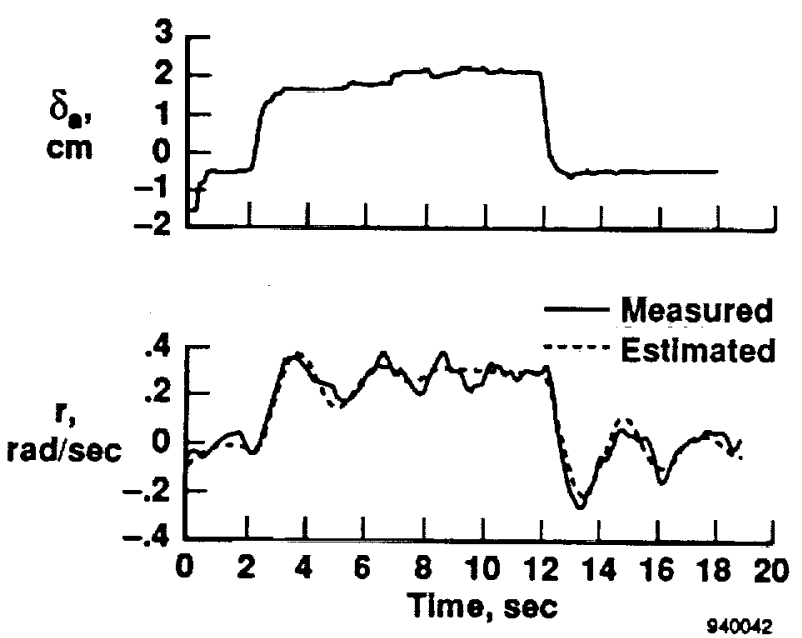

(a) Maneuver 1 .
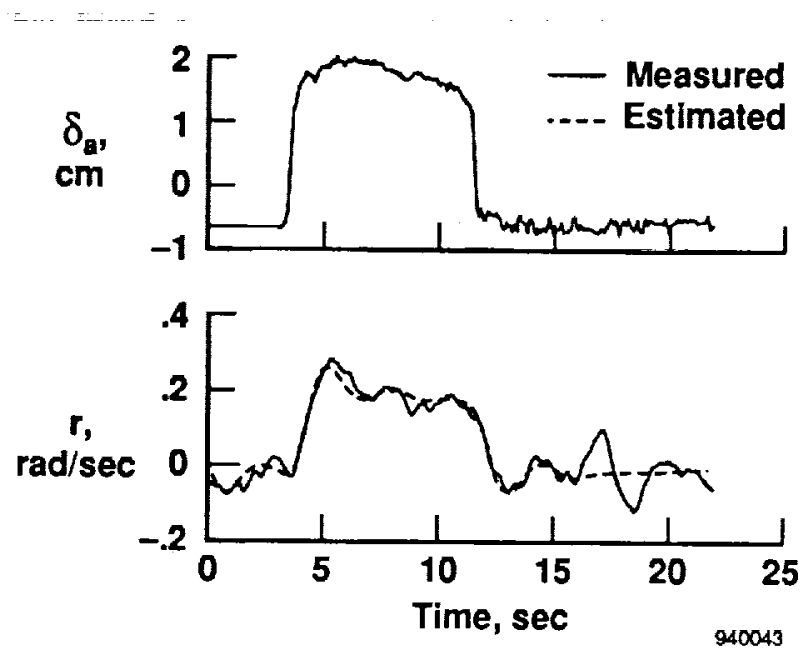

(b) Maneuver 2.

Figure 11. Comparison of measured and estimated (modeled) yaw rate response with aileron pulse input.

\section{Heading Angle Reconstruction}

Although the compass provides a good heading in steady flight, its output is unreliable during dynamic maneuvering because of its lag, magnetic dip, and saturation at large bank angles. The compass by itself was not usable for either postfight analysis or as a feedback signal. The solution was to combine both yaw rate and the compass as inputs to a modified complementary filter that reconstructed a heading angle for use as a feedback signal. The design of the modified complementary filter combines the wide bandwidth characteristics of the yaw rate gyro and the low drift characteristics of the electronic compass to give an excellent quality heading (output) that is suitable for feedback in either maneuvering or steady flight. The continuous time representation of the complementary filter (fig. 12) has the following state equation:

$$
\dot{\Psi}_{\text {filt }}=-\frac{1}{\tau} \Psi_{\text {fill }}+\frac{1}{\tau} \Psi_{\text {comp }}+r_{\text {gyro }}
$$

At large bank angles (and consequently large yaw rates, $\left|r_{\text {gyro }}\right|>0.2 \mathrm{rad} / \mathrm{sec}$ ), the compass signal was completely unreliable and unsuitable for use even with a complementary filter, and the filter was replaced with an open-loop integration of yaw rate

$$
\dot{\Psi}_{f i l t}=r_{g y r o}, \text { for: }\left|r_{g y r o}\right|>r_{l i m}
$$

The continuous-time solution was transformed to a discrete-time representation for implementation in the flight control computer. The state transition matrix ${ }^{6}$ transformed the continuous-time state equations to their discrete-time equivalent. The 25 samples/sec sampling rate was so much higher than the natural frequencies of the system that selection of the transformation method was not critical.

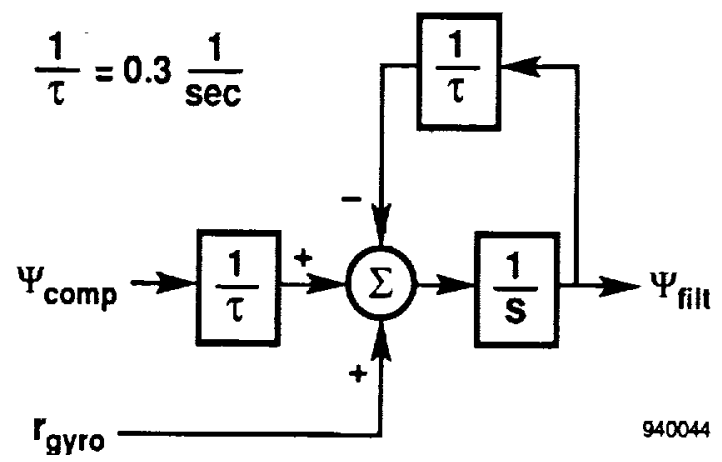

Figure 12. Continuous-time formulation of complementary filter. 


$$
\begin{aligned}
\Psi_{f i l t}(k+1)= & e^{-\frac{\Delta t}{\tau}} \Psi_{f i l l}(k) \\
& +\left(1-e^{-\frac{\Delta t}{\tau}}\right) \Psi_{c o m p}(k) \\
& +\tau\left(1-e^{-\frac{\Delta t}{\tau}}\right) r_{g y r o}(k) \\
& \text { for: }\left|r_{g y r o}(k)\right| \leq r_{l i m} \\
\Psi_{f i l l}(k+1)= & \Psi_{f i l l}(k)+\Delta t r_{g y r o}(k) \\
& \text { for: }\left|r_{g y r o}(k)\right|>r_{\text {lim }}
\end{aligned}
$$

Both state equations were combined to use a single state variable by scheduling the element gains with yaw rate to yield the modified complementary filter as implemented on the flight control computer. Figure 13 is a block diagram of the filter with numerical values for the element gains.

The improvement in bandwidth and correction of gross inaccuracies are illustrated in the time history plot (fig. 14) showing measured yaw rate from the gyro, measured heading from the compass, and reconstructed heading from the complementary filter. While the measured compass signal takes a few seconds to respond to the turn initiated about $t=20 \mathrm{sec}$, the reconstructed heading signal responds almost immediately. As the turn accelerates, the electronic compass hits its mechanical travel limit and the measured compass signal fails. The reconstructed heading signal is consistent with the yaw rate throughout the turn and smoothly transitions to the measured compass signal upon completion of the turn. The reconstructed heading is also unaffected by the apparent turbulence-induced yaw rate from about 90 to $140 \mathrm{sec}$.

\section{Directional Trim Alleviation}

The small parafoil has exhibited unexplained flightto-flight variations in directional trim. To counter this trim variation, a proportional integral derivative controller has been implemented in the autopilot software (fig. 5). The controller tracks a low-bandwidth commanded heading signal and uses the integral term to null out the effect of the trim variations. For the generalized parafoil control problem, this solution to the directional trim problem is analogous to having a system that works even with a poorly rigged parafoil.

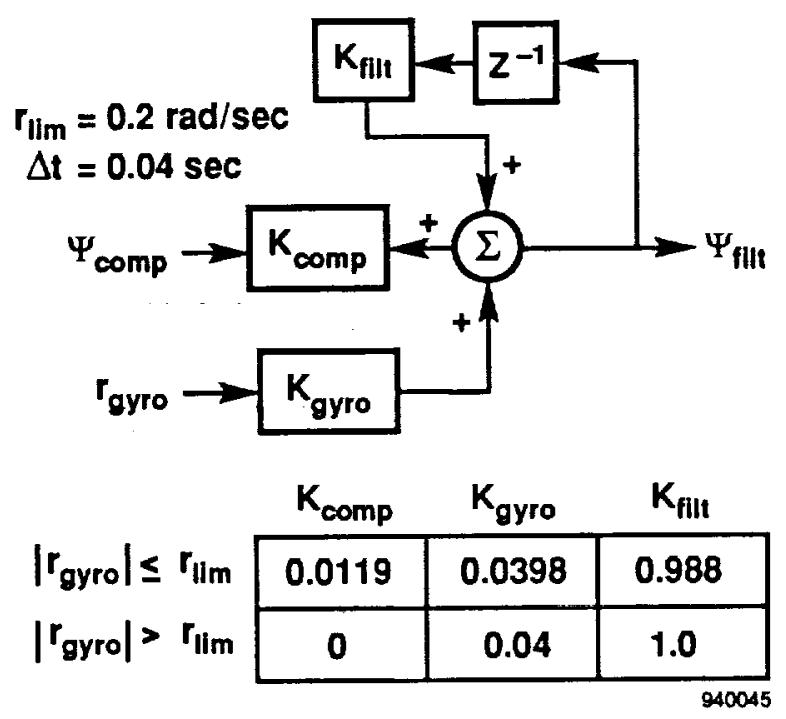

Figure 13. Discrete-time implementation of modified complementary filter.

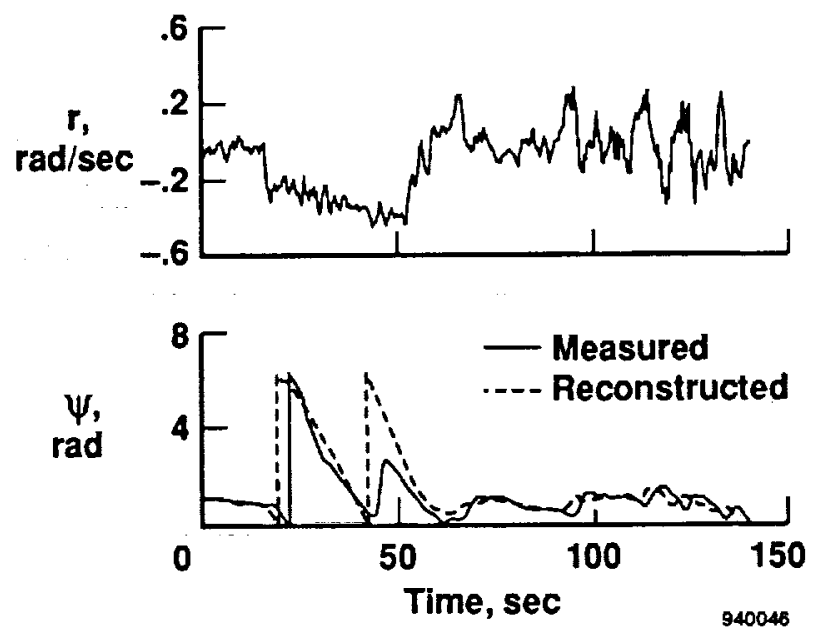

Figure 14. Measured heading angle and heading angle reconstructed with modified complementary filter.

\section{Alternative Flare}

For the alternative flare tests the vehicle was flown in the manual mode. At approximately $10 \mathrm{ft}$ above the ground the pilot released the lever arm pins and initiated the flare. A flight demonstration qualitatively showed the technique to be viable. This approach would greatly reduce the actuator requirements for a full-scale vehicle. 


\section{Future Work}

The process planned for designing the autolanding controller is similar to that used for designing the heading tracker. An altitude-to-elevator (symmetric control line) transfer function will be obtained using parameter estimation techniques. The ultrasonic range sensor will be installed as the ground relative altitude sensor. The ultrasonic sensor, however, is of limited bandwidth and resolution and will likely need enhancement from either a normal accelerometer or pitch-rate gyro. This approach will allow for the dynamics of the flare maneuver to be modeled and the autolanding controller to be designed.

\section{Concluding Remarks}

A program was conducted to determine the feasibility of the autonomous recovery of a spacecraft using a parafoil system for the final stages of entry from space. The feasibility was studied using a generic subscale flight model spacecraft that weighed approximately $54 \mathrm{~kg}(120 \mathrm{lb})$ and was flown under a ram-air parachute. Key elements of the vehicle included Global Positioning System (GPS) guidance for the autonomous navigation, a flight control computer, an electronic compass, a yaw rate gyro, and the onboard data recording. A flight test program is being used to develop and refine the vehicle. The development has included several ground tests, manual flight using a radio uplink, and limited testing of the autonomous mode. The concept of a flexible deployable system that uses autonomous navigation is proving to be a practical technique for recovering spacecraft. An altemative flare technique using the vehicle's weight to pull down the control lines was shown to be viable. Work toward a fully autonomous flight with a precision flare and landing into the wind is in progress.

\section{Acknowledgment}

The authors acknowledge the contributions of Wesley S. Hughes (1946-1993). Without his timely assistance a project of this scope would not have been possible.

\section{References}

'Sim, Alex G., James E. Murray, David C. Neufeld, and R. Dale Reed, The Development and Flight Test of a Deployable Precision Landing System for Spacecraft Recovery, NASA TM-4525, Sept. 1993.

${ }^{2}$ Brown, Glen J., "Parafoil Steady Turn Response to Control Input," AIAA-93-1241, 1993.

${ }^{3}$ Ljung, Lennart, System Identification Toolbox User's Guide, The MathWorks, Inc., July 1991.

${ }^{4}$ Global Positioning System, 3 vols., Washington, DC: Institute of Navigation, 1980-1986.

${ }^{5}$ Geenen, Robert J., Bryan J. Moulton, and Edward A. Haering, Jr., "A System for Testing Airdata Probes at High Angles of Attack Using a Ground Vehicle," AIAA-91$0088,1991$.

${ }^{6}$ Brogan, William L., Modern Control Theory, PrenticeHall, Inc./Quantum Pub., Inc., Englewood Cliffs, NJ $07632,1985$.

${ }^{7}$ Franklin, Gene F., J. David Powell, and Abbas EmamiNaeini, Feedback Control of Dynamic Systems, AddisonWesley Pub. Co., Inc., 1986 (printed with corrections May 1987). 


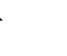


Public reponting burden for this collection of Inlormation is estlmated to average 1 hour per response, including the time lor reviewing Instructions, searching existing data sources, gathering and maintaining the data needed, and completing and reviewing the collection of intormation. Send comments regarding this burden estimate or any other aspect of this collection of information, Including suggestions for reducing this burden, to Washington Headquarters Services, Directorate for Information Operations and Reports, 1215 Jefferson Davis Highway, Sulte 1204, Arlington, VA 22202-4302, and to the Ofloe of Management and Budget. Papenwork Reduction Project (0704-0188). Washington, DC 20503.

\begin{tabular}{|l|l|l|}
\hline 1. AGENCY USE ONLY (Leavo blank) & 2. REPORT DATE & 3. REPORT TYPE AND DATES COVERED
\end{tabular}

\begin{tabular}{|l|l|l}
\hline July 1994 & Technical Memorandum
\end{tabular}

4. TITLE AND SUBTITLE

Further Development and Flight Test of an Autonomous Precision Landing System Using a Parafoil

6. AUTHOR(S)

James E. Murray, Alex G. Sim, David C. Neufeld, Patrick K. Rennich, Stephen R. Norris, and Wesley S. Hughes

7. PERFORMING ORGANIZATION NAME(S) AND ADDRESS(ES)

NASA Dryden Flight Research Center

P.O. Box 273

Edwards, California 93523-0273

9. SPONSORING/MONOTORING AGENCY NAME(S) AND ADDRESS(ES)

National Aeronautics and Space Administration

Washington, DC 20546-0001
5. FUNDING NUMBERS

WU 505-68-50

8. PERFORMING ORGANIZATION REPORT NUMBER

H-1987

10. SPONSORING/MONITORING AGENCY REPOAT NUMBER

NASA TM-4599

\section{SUPPLEMENTARY NOTES}

This was prepared as AIAA-94-2141 for the 6th Biennial Flight Test Conference, Colorado Springs, CO, June 20-23, 1994.

12a. DISTRIBUTION/AVAILABILITY STATEMENT

12b. DISTRIBUTION CODE

Unclassified-Unlimited

Subject Category 02

13. ABSTRACT (Maximum 200 words)

NASA Dryden Flight Research Center and NASA Johnson Space Center are jointly conducting a phased program to determine the feasibility of the autonomous recovery of a spacecraft using a ram-air parafoil system for the final stages of entry from space to a precision landing. The feasibility is being studied using a flight model of a spacecraft in the generic shape of a flattened biconic that weighs approximately $120 \mathrm{lb}$ and is flown under a commercially available ram-air parafoil. Key components of the vehicle include the Global Positioning System (GPS) guidance for navigation, a flight control computer, an electronic compass, a yaw rate gyro, and an onboard data recorder. A flight test program is being used to develop and refine the vehicle. The primary flight goal is to demonstrate autonomous flight from an altitude of $3,000 \mathrm{~m}(10,000 \mathrm{ft})$ with a lateral offset of $1.6 \mathrm{~km}$ $(1.0 \mathrm{mi})$ to a precision soft landing. This paper summarizes the progress to date. Much of the navigation system has been tested, including a heading tracker that was developed using parameter estimation techniques and a complementary filter. The autoland portion of the autopilot is still in development. The feasibility of conducting the flare maneuver without servoactuators was investigated as a means of significantly reducing the servoactuator rate and load requirements.

\begin{tabular}{|c|c|c|c|}
\hline 14. SUBJECT TERMS & & & $\begin{array}{l}\text { 15. NUMBER OF PAGES } \\
13\end{array}$ \\
\hline Aeroclasticity, Flight $\mathrm{f}$ & er testing, Ground vibratio & sting & 16. PRICE CODE \\
\hline $\begin{array}{l}\text { 17. SECURITY CLASSIFICATION } \\
\text { OF REPORT } \\
\text { Unclassified }\end{array}$ & $\begin{array}{l}\text { 18. SECUAITY CLASSIFICATION } \\
\text { OF THIS PAGE } \\
\text { Unclassified }\end{array}$ & $\begin{array}{l}\text { 19. SECURITY CLASSIFICATION } \\
\text { OFABSTRACT } \\
\text { Unclassified }\end{array}$ & $\begin{array}{l}\text { 20. LIMITATION OF ABSTRACT } \\
\text { Unlimited }\end{array}$ \\
\hline & & & \\
\hline
\end{tabular}

